\title{
Modelling Occupancy Rates in Croatian Hotel Industry
}

\author{
Tea Baldigara ${ }^{1} \&$ Marija Koic ${ }^{1}$ \\ ${ }^{1}$ Faculty of Tourism and Hospitality Management, Opatija, Croatia \\ Correspondence: Tea Baldigara, Faculty of Tourism and Hospitality Management, Primorska 42, 51410 Opatija, \\ Croatia. Tel: 385-51-294-684. E-mail: teab@fthm.hr
}

Received: April 13, 2015

Accepted: May 11, 2015

Online Published: May 17, 2015

doi:10.5430/ijba.v6n3p121

URL: http://dx.doi.org/10.5430/ijba.v6n3p121

\begin{abstract}
The present study aims to analyse and model the net occupancy rates of bed-places in the Croatian hotel industry in the period from January 2005 to August 2014. For these purposes three models of generating time-series forecasts were used: the seasonal Naive model, the Holt-Winters exponential model and the seasonal autoregressive integrated moving average model. The empirical results show that the used time-series models performed well in terms of MAPE and that the Holt-Winters model outperformed the seasonal naive and the seasonal ARIMA model.
\end{abstract}

Keywords: Croatian hotel industry, occupancy rates, modelling, time-series models

\section{Introduction}

Besides tourism, hotel industry is a significant source of profit in Croatian economy. According to the data from the Croatian Bureau of Statistics, the number of collective accommodation facilities in 2012 increased for 137 units and the number of bed places increased for about 1000. In 2012 there was in the Croatian accommodation sector, both collective and private, a total of 305 thousand rooms, 880 thousand beds with the average occupancy rate of 71.3 days. Within the whole Croatian accommodation sector, hotels registered the highest occupancy rate of 128 days or $47 \%$ and the average stay amounted to 3.8 days. Although Croatian hotel industry has almost reached the pre-war level of tourist turnover, Croatian hotels account for merely $15 \%$ of the total tourist accommodation facilities. An accurate modeling and forecasting of hotel occupancy rates, revenue per room, reservation forecasting, number of tourist nights, number of beds and rooms and other elements are important in all areas of hotel operations and are taken into serious consideration when planning and modelling demand. Implementation of quantitative methods should be considered as a core prerequisite of improving performance in the Croatian hotel industry.

\section{Literature Review}

A comprehensive desk research and literature review showed that a significant number of recent researches and studies deal with the issue of the benefits of applying quantitative methods in analysing hotel performance indicators. Lim and Chan (2009) examined the seasonality of hotel-motel occupancy in New Zealand and used the Box-Jenkins approach to forecast hotel-motel room nights. El Gayaretal. (El Gayaretal, 2014) researched the implementation of advanced forecasting and optimization methods in maximization the hotel room revenue. Zakhary et al. (Zakhary, et al., 2009) used Monte Carlo simulation to generate forecasts for room demand for Plaza Hotel, Alexandria, Egypt. Law (Law, 1998) used a neural network approach to forecast hotel occupancy in Hong Kong. Jeffery and Barden (Jeffrey and Baredn, 2000) used time-series analysis of daily room occupancy rates in 91 hotels in England from January 1992 to December 1994 to analyse the week occupancy performance in the hotel industry in England. Andrew et al. (Andrew et al., 1990) empirically examined the use of Box-Jenkins models and exponential smoothing in forecasting monthly hotel occupancy rates. Phumchusri and Mongkolkul (Phumchusri and Mongkolkul, 2012) proposed a multiple regression model for the hotel room demand forecasting. Although, Croatia is a predominantly tourism oriented country, in reviewing the literature there has been noted a lack of systematic and detailed domestic quantitative researches focused on analysing the patterns and core determinants of the Croatian hotel industry. In future, more sophisticated quantitative, both extrapolative and causal forecasting techniques, should be applied to investigate, model and forecast tourism demand, especially international, in Croatia. The study wants to emphasize that, given the importance of tourism for Croatia's economic development, there is a lack of quantitative approaches to tourism demand modelling and forecasting. Profoundly aware that modelling tourism demand is a challenging and controversial issue, that the adequacy of a forecasting model is valued according to its out-of- sample forecasts, and 
that is still difficult to indicate which model or class of models is more adequate for tourism demand modelling, the authors of this study wished to highlight the necessity of more systematic quantitative analysis of Croatia's tourism demand in all its determinants.

\section{Data and Methodology}

This study examines the net occupancy rate of bed-places in hotels and similar establishment in Croatia. It has to be noticed that this study considers only hotels as the most important representatives of the whole collective accommodation sector. Data are monthly and cover the period from January 2005 to August 2014 and are taken from the European Commission Eurostat Database. According to the Eurostat the net occupancy of bed places is obtained by dividing the total number of overnight stays by the number of the bed places on offer (excluding extra beds) and the number of days when the bed places are actually available for use (net of seasonal closures and other temporary closures for decoration, by police order, etc.). The result is multiplied by 100 to express the occupancy rate as a percentage.

(http://epp.eurostat.ec.europa.eu/cache/ITY_SDDS/en/tour_occ_esms.htm)

Figure 1 shows the actual data for net occupancy rate of bed-places in Croatian hotel industry in the analysed period used in the model building process.

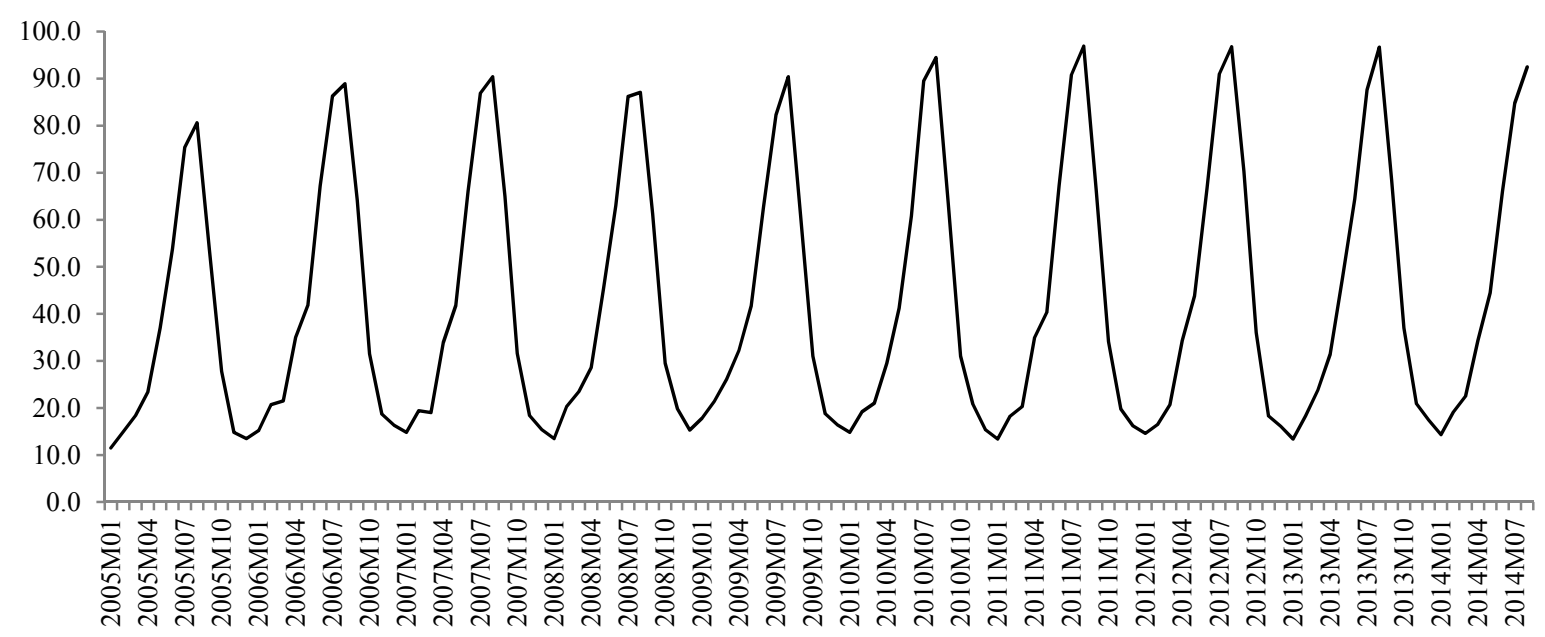

Figure 1. Net occupancy rate of bed-places in hotels and similar accommodation in Croatia form January 2005 to August 2014

A first look at the figure reveals a high degree of seasonality and a slight upward trend in time. It is well known that the hotel sector in Croatia assumes pronouncedly seasonal features. In fact, the net occupancy rates of bed-places are at their maximum levels in the summer period till July to August, with a drastic fall in the period from October to May. In analysing and modelling net occupancy rate of bed-places in Croatian hotels, it is therefore important to consider its seasonal character. Therefore, specific quantitative methods that take into account this pronounced seasonal component, should be used to model the empirical time-series values. In literature, there are different approaches for dealing with seasonality. Among the different models, built to capture the seasonal component, the Seasonal Naïve, the Holt-Winters and the Seasonal ARIMA modelling are used in this study. The following describes the theoretical concepts of the modelling techniques adopted in this study and the essentials of the selected forecasting error for evaluating the forecasting accuracy.

\section{The Seasonal Naive Model}

The seasonal naive model is used with seasonal data and postulates that the next period's value is equal to the value of the same period in the previous year. The seasonal naive model is expressed as follows:

$$
F_{t}=A_{t-m}
$$


where

$\mathrm{F}=$ forecast value

$\mathrm{A}=$ actual value

$\mathrm{t}=$ some period time

$\mathrm{m}=$ number of periods in a year

The Naïve concepts are usually used as a benchmark forecast, namely for comparison with the forecast generated by other more sophisticated forecasting methods.

Triple exponential smoothing: the Holt-Winters'trend and seasonality method

The Holt-Winters' trend and seasonality method employs triple exponential smoothing: one equation for the level, one for the trend and one for the seasonality. The following equations are associated with all the named elements (Note 1):

Level:

$$
L_{t}=\alpha \cdot \frac{Y_{t}}{S_{t-s}}+(1-\alpha)\left(L_{t-1}+b_{t-1}\right)
$$

Trend:

$$
b_{t}=\beta\left(L_{t}-L_{t-1}\right)+(1-\beta) b_{t-1}
$$

Seasonal:

$$
S_{t}=\gamma \frac{Y_{t}}{L_{t}}+(1-\gamma) S_{t-s}
$$

Forecast:

$$
F_{t+h}=\left(L_{t}+h b_{t}\right) S_{t-s+h}
$$

where

$\mathrm{L} \quad=$ level of the series

$\alpha \quad=$ level smoothing constant between 0 and 1

A = actual value

$\mathrm{s} \quad=$ number of seasonal periods in a year

$\mathrm{b} \quad=$ trend of the series

$\beta=$ seasonal smoothing constant between 0 and 1

$\mathrm{S}=$ seasonal component

$\gamma \quad=$ seasonal smoothing constant between 0 and 1

$\mathrm{t}=$ some period time

$\mathrm{h}=$ number of time periods ahead to be forecast

The initialization, as the process of providing a forecast value for the first period, can be approached using the following equations:

Initial level:

$$
L_{s}=\frac{A_{1}+A_{2}+\cdots+A_{s}}{s}
$$

Initial trend:

$$
b_{s}=\frac{1}{S}\left(\frac{A_{s+1}-A_{1}}{s}+\frac{A_{s+2}-A_{2}}{s}+\cdots+\frac{A_{s+s}-A_{s}}{S}\right)
$$

Seasonal indices for the first year:

$$
S_{1}=\frac{A_{1}}{L_{s}}, S_{2}=\frac{A_{2}}{L_{s}}, \ldots, S_{s} \frac{A_{s}}{L_{s}}
$$


Alternatively, the initial level, initial trend and the seasonal factors can be obtained by fitting a least squares trend line of the historical data.

\section{The Seasonal Autoregressive Integrated Moving Average Model}

Seasonality in economic time-series is a regular and quite common pattern of changes that repeats over $\mathrm{S}$ time period, where $\mathrm{S}$ is the number of time periods until the pattern repeats again. Seasonal Autoregressive Integrated Moving Average (SARIMA) processes are designed to model time series with trends, seasonal patterns and short time correlation. They have been developed from the standard model of Box and Jenkins (1970) and incorporate both seasonal autoregressive and moving average factors into the modelling process. In order to deal with seasonality, ARIMA processes have been generalized and SARIMA models have then been formulated. The seasonal ARIMA (the SARIMA) models incorporate both non-seasonal and seasonal factors in a multiplicative model as follows:

$$
\operatorname{ARIMA}(p, d, q) \times(P, D, Q) S
$$

where:

$$
\begin{aligned}
& p=\text { non-seasonal AR order } \\
& d=\text { non-seasonal differencing } \\
& q=\text { non-seasonal MA order } \\
& P=\text { seasonal AR order } \\
& D=\text { seasonal differencing } \\
& Q=\text { seasonal MA order } \\
& S=\text { time span of repeating seasonal pattern }
\end{aligned}
$$

The seasonal autoregressive integrated moving average model of Box and Jenkins (1970) is given by

$$
\phi(B) \Phi\left(B^{s}\right)(1-B)^{d}\left(1-B^{s}\right)^{D} Y_{t}=\Theta_{0}+\theta(B) \Theta\left(B^{s}\right) \varepsilon_{t}
$$

where

$\begin{array}{lll}\phi(B) & =1-\emptyset_{1} B-\emptyset_{2} B^{2}-\cdots-\emptyset_{p} B^{p} & \text { is the p-order non seasonal AR model } \\ \theta(B) & =1-\theta_{1} B-\theta_{2} B^{2}-\cdots-\theta_{q} B^{q} & \text { is the q-order non seasonal MA model } \\ \Phi\left(B^{s}\right) & =1-\Phi_{1} B^{s}-\Phi_{2} B^{2 s}-\cdots-\Phi_{P} B^{P s} & \text { is the P-order seasonal AR model } \\ \Theta\left(B^{s}\right) & =1-\Theta_{1} B^{s}-\Theta_{2} B^{2 s}-\cdots-\Phi_{Q} B^{Q s} & \text { is the Q-order seasonal MA model } \\ (1-B)^{d} & \text { denotes the non-seasonal differencing of order d } \\ \left(1-B^{s}\right)^{D} & \text { denotes the seasonal differencing of order D } \\ \varepsilon_{t} & \text { is the error term } \sim \text { IID }\left(0, \sigma^{2}\right) \\ B & \text { is the backward shift } \\ S & \text { is the seasonal order }\end{array}$

To evaluate the forecast accuracy the Mean Absolute Percentage Error (MAPE) is expressed in generic percentage terms and it is computed by the following expression:

$$
M A P E=\frac{1}{n} \sum_{t=1}^{n} \frac{\left|\left(A_{t}-F_{t}\right)\right|}{A_{t}} \cdot 100
$$

where

$t=$ some time period

$A=$ actual value of the variable being forecast

$F=$ forecast value

MAPE is a simple measure that permits to compare the accuracy of different models, with different time periods and numbers of observations. 


\section{Empirical Results and Discussion}

In this section the comparison of the results obtained using the Seasonal Naive model, the Holt-Winters model and the SARIMA model in analysing the net occupancy rate of bed-places in Croatian hotels in the period from January 2005 to August 2014 international tourism demand in Croatia, is discussed.

\section{The Seasonal Naive model}

The Seasonal Naive model was defined under the assumption that the net occupancy rate for bed-places at time $t$ was the same as the value at time t-12. The MAPE of 6,582 for the performed Seasonal Naive model indicates a high accuracy in forecasting the empirical data.

\section{The Holt-Winters model}

In modelling the empirical data of the net occupancy rate of bed-places in Croatian hotels in the analysed time span the multiplicative Holt-Winters model was used. The results are reported in Table 1.

Table 1. Holt-Winters modelling results for the net occupancy rate of bed-places in Croatian hotels time-series

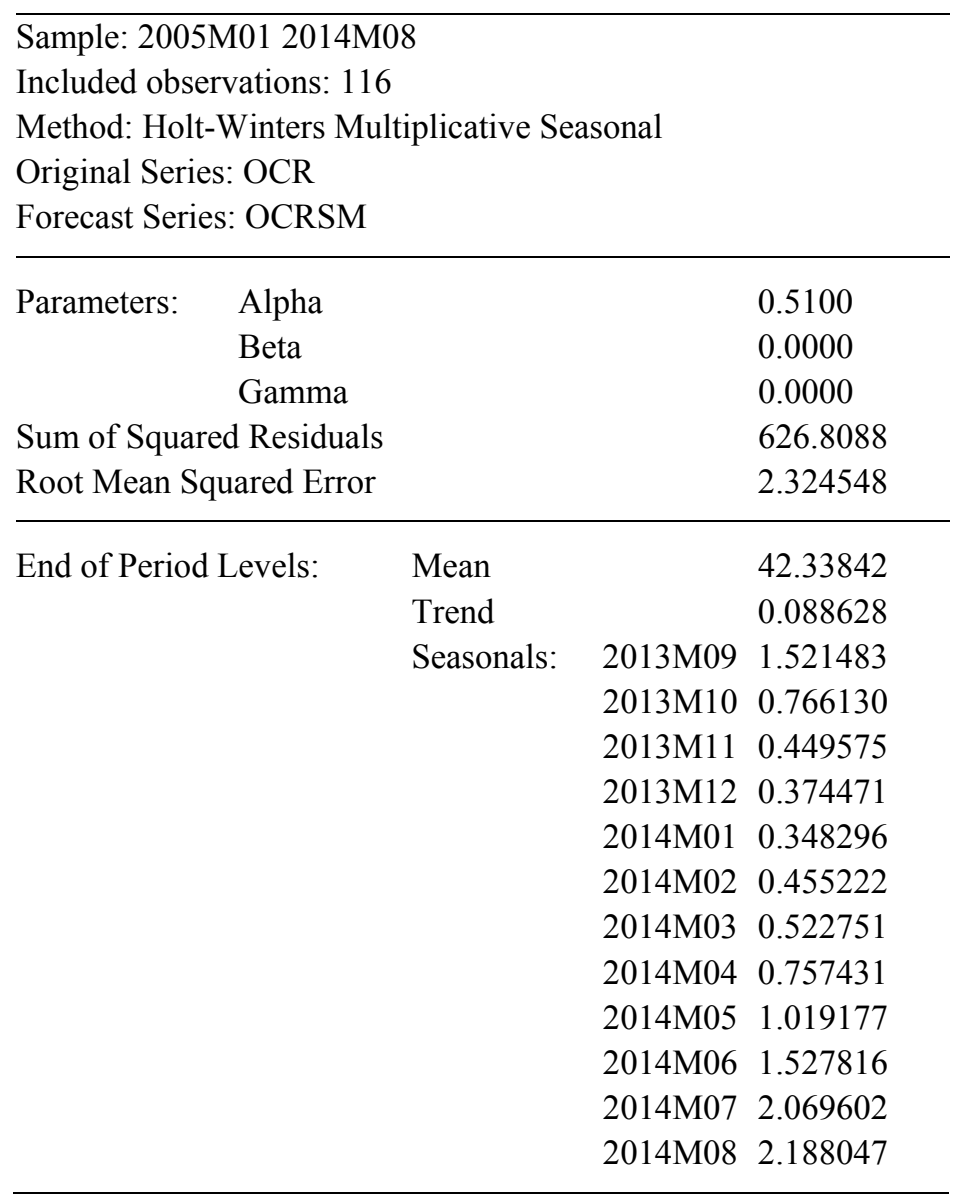

The smoothing procedure resulted with the following smoothing constants $\alpha=0,5, \beta=0$ and $\gamma=0$. The zero values for $\beta$ and $\gamma$ mean that the trend and the seasonal components are estimated as fixed and not changing. According to Lee, Song and Mjelde (Lee, Song, Mjelde, 2008) a value of 0,5 for the smoothing constant $\alpha$ indicates that the current single smoothed values were predicted based on the moderate weight on both current values adjusted for seasonality and previous values smoothed and trend values. The smoothing constant $\beta=0$ implies that the current trend values are a function of the previous trend values without considering the difference in the smoothed values. The smoothing constant $\gamma=0$ denotes that the current seasonal component is a function of the previous seasonal without considering the current values to be adjusted by the smoothed values. The designed model minimizes the sum of squares and shows a highly accurate performance in modelling the empirical data with a MAPE of 5,775. 


\section{The Seasonal Autoregressive Integrated Moving Average model}

Before approaching the selection of the appropriate seasonal autoregressive integrated moving average model the empirical data are tested for stationarity performing the ADF test. The hypotheses of the Augmented Dickey-Fuller test are:

$$
\begin{gathered}
H_{0}: \gamma=0, \text { there is a unit } \operatorname{root}(\rho=1) \\
H_{0}: \gamma<0, \text { there is no unit } \operatorname{root}(\rho<1)
\end{gathered}
$$

The testing results are reported in the next table.

\begin{tabular}{|c|c|c|c|}
\hline \multicolumn{4}{|c|}{$\begin{array}{l}\text { Null Hypothesis: OCR has a unit root } \\
\text { Exogenous: Constant, Linear Trend } \\
\text { Lag Length: } 12 \text { (Automatic - based on SIC, maxlag=12) }\end{array}$} \\
\hline & & t-Statistic & Prob.* \\
\hline \multicolumn{2}{|c|}{ Augmented Dickey-Fuller test statistic } & -4.248873 & 0.0055 \\
\hline Test critical values: & $\begin{array}{l}1 \% \text { level } \\
5 \% \text { level } \\
10 \% \text { level }\end{array}$ & $\begin{array}{l}-4.049586 \\
-3.454032 \\
-3.152652\end{array}$ & \\
\hline
\end{tabular}

Table 2. Original time-series unit root testing results

With the null hypotheses is assumed the nonstationarity, which is the presence of a unit root in the time-series. The ADF test statistics is $-4,248873$ and is smaller than the critical values at $1 \%, 5 \%$ and $10 \%$ level. The hypothesis of stationarity can be therefore accepted.

Among the analyzed models the seasonal $(1,1,0)(2,1,0) \times 12$ ARIMA model was identified as the most adequate because it presented the smallest AIC, SBC and HQ Information criterion and the smallest mean absolute percentage error (MAPE). The estimation results of the selected model are reported in the next table.

\begin{tabular}{|c|c|c|c|c|}
\hline \multicolumn{5}{|c|}{$\begin{array}{l}\text { Dependent Variable: D(OCR,1,12) } \\
\text { Method: Least Squares } \\
\text { Sample (adjusted): } 2008 \mathrm{M} 03 \text { 2014M08 } \\
\text { Included observations: } 78 \text { after adjustments } \\
\text { Convergence achieved after } 8 \text { iterations }\end{array}$} \\
\hline Variable & Coefficient & Std. Error & t-Statistic & Prob. \\
\hline $\mathrm{AR}(1)$ & -0.603928 & 0.092626 & -6.520063 & 0.0000 \\
\hline SAR(12) & -0.301336 & 0.110608 & -2.724366 & 0.0080 \\
\hline $\operatorname{SAR}(24)$ & -0.357666 & 0.105739 & -3.382547 & 0.0011 \\
\hline R-squared & 0.529087 & \multicolumn{2}{|c|}{ Mean dependent var } & -0.065385 \\
\hline $\begin{array}{l}\text { Adjusted R-squared } \\
\text { S.E. of }\end{array}$ & 0.516529 & \multicolumn{2}{|c|}{ S.D. dependent var } & 3.817520 \\
\hline regression & 2.654400 & \multicolumn{2}{|c|}{ Akaike info criterion } & 4.828017 \\
\hline Sum squared resid & 528.4380 & \multirow{3}{*}{\multicolumn{2}{|c|}{$\begin{array}{l}\text { Schwarz criterion } \\
\text { Hannan-Quinn criter. }\end{array}$}} & 4.918659 \\
\hline Log likelihood & -185.2927 & & & 4.864303 \\
\hline Durbin-Watson stat & 2.075115 & & & \\
\hline Inverted AR Roots & $\begin{array}{l}.95-.15 \mathrm{i} \\
.75+.60 \mathrm{i}\end{array}$ & $\begin{array}{l}.95+.15 \\
.75-.601\end{array}$ & $\begin{array}{l}.89-.35 \mathrm{i} \\
.60+.75 \mathrm{i}\end{array}$ & $\begin{array}{l}.89+.35 \mathrm{i} \\
.60-.75 \mathrm{i}\end{array}$ \\
\hline
\end{tabular}

Table 3. Parameter estimation results for the selected seasonal $(1,1,0)(2,1,0)_{\times 12}$ ARIMA model 


$\begin{array}{lccc}.35-.89 \mathrm{i} & .35+.89 \mathrm{i} & .15+.95 \mathrm{i} & .15-.95 \mathrm{i} \\ -.15-.95 \mathrm{i} & -.15+.95 \mathrm{i} & -.35+.89 \mathrm{i} & -.35-.89 \mathrm{i} \\ -.60+.75 \mathrm{i} & -.60-.75 \mathrm{i} & -.60 & -.75+.60 \mathrm{i} \\ -.75-.60 \mathrm{i} & -.89+.35 \mathrm{i} & -.89-.35 \mathrm{i} & -.95-.15 \mathrm{i} \\ -.95+.15 \mathrm{i} & & & \end{array}$

The parameter of the estimated model are all significant at $5 \%$ level and the adjusted $R^{2}$ of 0,529087 shows a quite good model fit. The selected model is tested for invertibility by using the inverted AR/MA roots. The results are shown in the table below.

Table 4. Invertibility results testing for the selected seasonal $(1,1,0)(2,1,0)_{\mathrm{x} 12}$ ARIMA model

\begin{tabular}{|c|c|c|c|}
\hline \multicolumn{4}{|c|}{$\begin{array}{l}\text { Inverse Roots of AR/MA Polynomial(s) } \\
\text { Specification: D(OCR, 1, 12) AR(1) SAR(12) SAR(24) } \\
\text { Sample: 2005M01 2014M08 } \\
\text { Included observations: } 78\end{array}$} \\
\hline AR Root(s) & & Modulus & Cycle \\
\hline $0.747536 \pm$ & $0.599232 \mathrm{i}$ & 0.958065 & 9.298485 \\
\hline $0.347769 \pm$ & $0.892718 \mathrm{i}$ & 0.958065 & 5.238956 \\
\hline $0.892718 \pm$ & $0.347769 \mathrm{i}$ & 0.958065 & 16.91410 \\
\hline$-0.747536 \pm$ & $0.599232 \mathrm{i}$ & 0.958065 & 2.548059 \\
\hline$-0.599232 \pm$ & $0.747536 \mathrm{i}$ & 0.958065 & 2.796855 \\
\hline$-0.892718 \pm$ & $0.347769 \mathrm{i}$ & 0.958065 & 2.268203 \\
\hline$-0.347769 \pm$ & $0.892718 \mathrm{i}$ & 0.958065 & 3.234966 \\
\hline $0.145182 \pm$ & $0.947001 \mathrm{i}$ & 0.958065 & 4.428915 \\
\hline$-0.145182 \pm$ & $0.947001 \mathrm{i}$ & 0.958065 & 3.646826 \\
\hline$-0.947001 \pm$ & $0.145182 \mathrm{i}$ & 0.958065 & 2.101772 \\
\hline $0.599232 \pm$ & $0.747536 \mathrm{i}$ & 0.958065 & 7.019731 \\
\hline $0.947001 \pm$ & $0.145182 \mathrm{i}$ & 0.958065 & 41.30342 \\
\hline-0.603928 & & 0.603928 & \\
\hline
\end{tabular}

No root lies outside the unit circle.

ARMA model is stationary.

As reported in Table 4 all the absolute values of the inverted AR and MA roots are smaller than one, the estimated model is therefore stationary and invertible as reported in the next figure.

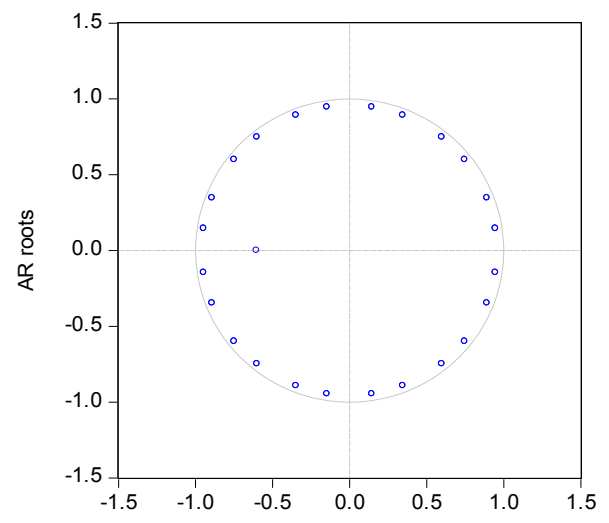

Figure 2. Inverse roots of AR/MA polynomial(s) 
After model identification and parameters estimation, the model is tested for the presence of autocorrelation. The autocorrelation and the partial correlations are reported in the next table.

Table 5. The autocorrelation and the partial correlation functions of the selected seasonal $(1,1,0)(2,1,0)_{\times 12}$ ARIMA model

\begin{tabular}{l} 
Sample: 2008M03 2014M08 \\
Included observations: 78 \\
Q-statistic probabilities adjusted for 3 ARMA term(s) \\
Autocorrelation \\
\hline
\end{tabular}

All the autocorrelation coefficients do not differ significantly from zero and they are within the 2-sigma limits $\left( \pm 2 \cdot \frac{1}{\sqrt{n}}\right)$ and there is no evidence of autocorrelation of residuals. The formal testing is performed by using the Breusch-Godfrey LM test.

Table 6. The Breusch-Godfrey test results

\begin{tabular}{llll}
\hline Breusch-Godfrey Serial Correlation LM Test: & \\
\hline F-statistic & 1.839650 & Prob. F(36,39) & 0.0321 \\
Obs*R-squared & 49.03354 & Prob. Chi-Square(36) & 0.0723
\end{tabular}

The results of the performed Breusch LM test show that the null hypothesis, of no serial correlation, can be accepted. The homoscedasticity of the residuals is tested using the Breusch-Pagan-Godfrey test.

Table 7. The Breusch-Pagan-Godfrey test results

\begin{tabular}{llll}
\hline Heteroskedasticity Test: & Breusch-Pagan-Godfrey & \\
\hline F-statistic & 0.587223 & Prob. F(3,74) & 0.6253 \\
Obs*R-squared & 1.813715 & Prob. Chi-Square(3) & 0.6120 \\
Scaledexplained SS & 2.030652 & Prob. Chi-Square(3) & 0.5661 \\
\hline
\end{tabular}


The results in Table 7 show that the residuals are homoscedastic and normally distributed, as shown in the figure below.

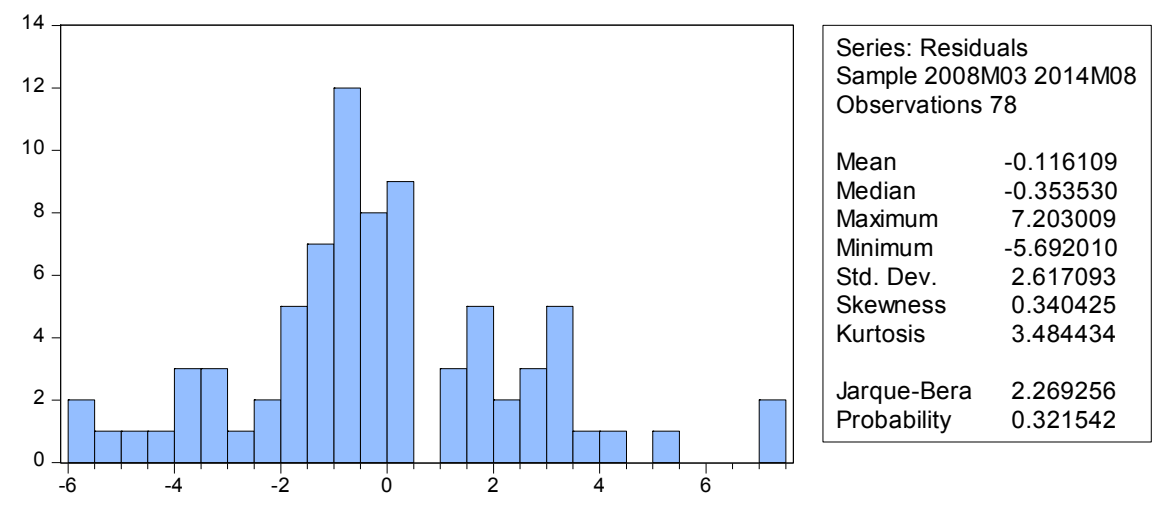

Figure 3. Residuals Testing - The Jarque-Berra Test

In order to test if the proposed seasonal ARIMA model is correctly specified the Ramsey RESET test, as a general misspecification test, is performed. The zero hypothesis is that the model is correctly specified. The results are show in the table below.

Table 8. Ramsey Reset test

Ramsey RESET Test

Equation: UNTITLED

Specification: D(OCR, 1, 12) AR(1) SAR(12) SAR(24)

Omitted Variables: Powers of fitted values from 2 to 5

\begin{tabular}{llll}
\hline & Value & df & Probability \\
\cline { 2 - 4 } F-statistic & 0.750215 & $(4,71)$ & 0.5612 \\
Likelihood ratio & 3.228954 & 4 & 0.5203 \\
\hline
\end{tabular}

The results confirm the correct specification of the model. Furthermore, the $R^{2}$ of the model show a quite reasonable model fitting. According to Baggio and Klobas (Baggio, Kobas, 2011) a MAPE value of 11,296 indicates a good model forecasting accuracy.

The three models used to model the net-occupancy rate of bed places in Croatian hotels fit the general movement of the analysed series during the entire sample period. The empirical results are reasonably good; the predicted values, in fact, are quite close to the actual values. The below figure illustrates the results of the selected models by comparing the actual data and the different forecasts obtained. 


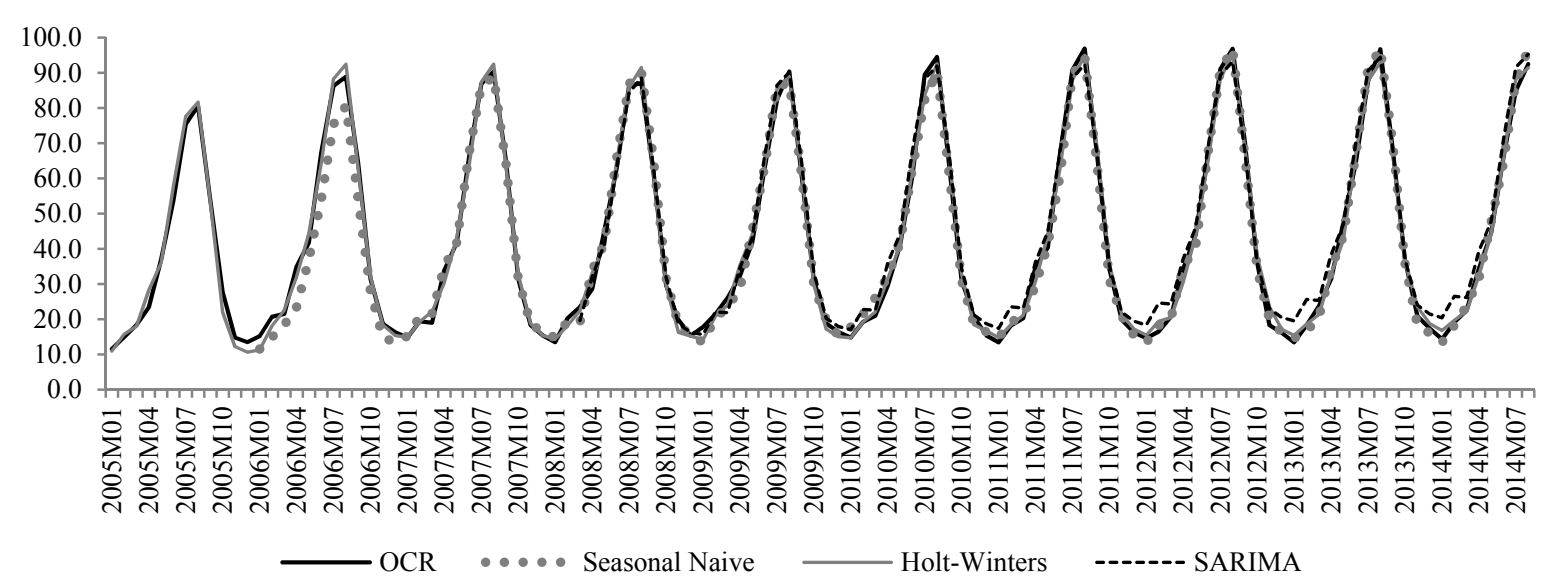

Figure 4. Modelling of net occupancy rate of bed-places: comparison of different time-series models

Empirical results and diagnostic testing of quantitative forecasting models of net-occupancy rates of bed places in Croatian hotels indicate that all three time-series model used in this study performed well in terms of MAPE. Table 9 reports the MAPE values and the forecasts obtained using the three extrapolative models.

Table 9. Errors of the selected forecasting techniques and forecasts for the August

\begin{tabular}{lcc}
\hline & MAPE & Forecast for 2014M08 \\
\hline Seasonal Naive & 6.582 & 96.7 \\
\hline Holt-Winters & 5.775 & 91.5 \\
\hline Seasonal ARIMA & 11.296 & 95.3 \\
\hline
\end{tabular}

The Holt-Winters model outperformed the seasonal ARIMA model. The empirical net-occupancy rate of bed places in Croatian hotels in August 2014 was 92,5\%.

\section{Conclusions}

Croatian economy is largely based on tourism. Besides tourism, hotel industry is a significant source of profit in Croatian economy. The aim of this study was to model the net-occupancy rate of bed places in Croatian hotels from January 2005 to August 2014. For this purpose three time-series models were used, i.e. the seasonal naive model, the Holt-Winters model and the seasonal autoregressive integrated moving average model. All performed diagnostic statistics showed that the specified models passed all the tests and that they fit the data reasonably well throughout the sample period. The empirical findings could be considered as starting points of future detailed and more systematic quantitative analysis of the Croatian hotel industry sector and its determinants.

\section{References}

Baggio, R., \& Klobas, J. (2011). Quantitative Methods in Tourism. Bristol: Channel View Publications.

Box, G., \& Jenkins, G. (1970). Time series analysis: Forecasting and control. San Francisco: Holden-Day.

Chang, C., Sriboonichtta, S., \& Wiboobpongse, A. (2009). Modelling and forecasting tourism from East Asia to Thailand under temporal and spatial aggregation. Mathematics and Computers in Simulation, 79(5), 1730-1744. http://dx.doi.org/10.1016/j.matcom.2008.09.006

Cho, V. (2003). A comparison of three different approaches to tourist arrival forecasting. Tourism Management, 24(3), 323-330.

Chu, F.L. (2009). Forecasting tourism demand with ARIMA-based methods. Tourism Management, 30(5), 740-751.

Dobre, I., \& Alexandru, A.A. (2008). Modelling unemployment rate using Box-Jenkins procedure. Journal of applied quantitative methods, 3(2), 156-166. 
Fernandes, P., Teixeira, J., Ferreira, J.M., \& Azevedo, S.G. (2008). Modelling Tourism Demand: A Comparative Study between Artificial Neural Networks and the Box-Jenkins Methodology. Romanian Journal of Economic Forecasting, 9(3), 30-50.

Frechtling, D.C. (2001). Forecasting Tourism Demand: Methods and Strategies. Woburn: Butterworth Heinemann, Elseivier plc group.

Gerard, S., \& Dharmaratne, G.S. (1995). Forecasting tourists' arrivals in Barbados. Annals of Tourism Research, 22(4), 804-818.

Jeffrey, D., \& Barden, R.R.D. (2000). An analysis of dailx occupancy performance: a basis for effective hotel marketing?. International Journal of Contemporary Hospitality Management, 12(3), 179-189. http://dx.doi.org/10.1108/09596110010320715

Lee, C.K., Song, H.J., \& Mjelde, J.W. (2008). The forecasting of International Expo tourism using quantitative and $\begin{array}{lllll}\text { qualitative } & \text { Tochniques. } & \text { 1084-1098. }\end{array}$ http://dx.doi.org/10.1016/j.tourman.2008.02.007

Lim, C., \& Chan, F. (2011). An econometric analysis of hotel-motel room nights in New Zealand with stochastic seasonality. International Journal of Revenue Management, 5(1), 63-83. http://dx.doi.org/10.1504/IJRM.2011.038619

Lim, C., \& McAleer, M. (2001). Time series forecasts of international tourism demand to Australia. Discussion paper (533), The Institute of Social and Economic Research Osaka University, Osaka.

Lim, C., \& Pan, G.W. (2005). Inbound tourism developments and patterns in China. Mathematics and Computers in Simulation, 68(5-6), 499-507. http://dx.doi.org/10.1016/j.matcom.2005.02.004

Lin, C., Chen, H., \& Lee, T. (2011). Forecasting Tourism Demand Using Time Series, Artificial Neural Networks and Multivariate Adaptive Regression Splines: Evidence from Taiwan. International Journal of Business Administration, 2(2), 14-24. http://dx.doi.org/10.5430/ijba.v2n2p14

Loganathan, N., \& Yahaya, I. (2010).Forecasting International Tourism Demand in Malaysia Using Box-Jenkins Sarima Application. South Asian Journal of Tourism and Heritage, 3(2), 55-70.

O’Niel, M. (2003). Tourism Maturity and Demand: Jamaica, Research Services Department. Research and Economic Programming Division. Work in Progress.Bank of Jamaica.

Phumchusri, N. \& Mongkolkul, P. (2012). Hotel Room Demand Forecasting via Observed Reservation Information. Proceedings of the Asia Pacific Industrial Engineering \& Management System Conference. Retreived March 20, 2015, from http://www.apiems.org/conf2012/conf2012/T5D5.pdf

Shen, S., Li, G., \& Song, H. (2011). Combination Forecasts of International Tourism Demand. Annals of Tourism Research, 1(38), 72-89.

Song, H., \& Li, G. (2008). Tourism demand modelling and forecasting - A review of recent research.Tourism Management, 29, 203-220. http://dx.doi.org/10.1016/j.tourman.2007.07.016

Song, H., Witt, S., \& Gang, L. (2012). The Advanced Econometrics of Tourism Demand. Routledge, Lonodn.

Weisang, G., \& Awazu, Y. (2008). Vagaries of the Euro: an Introduction to ARIMA Modelling. CS-BIGS, 2(1), 44-45. Retrieved January 4, 2012, from http://www.bentley.edu/csibgs/vol2-1/jaggia.pdf

William, P., Andrew, W.P., Cranage, D.A., \& Kwor, L.C. (1990). Forecasting Hotel Occupancy Rates with Time Series Models: An Empirical Analysis. Journal of Hospitality \& Tourism Research, 14, 173-182. http://dx.doi.org/10.1177/109634809001400219

Zakhary, A., Atiya, A.F., El-Shishiny, H., \& El Gayar, N. (2009). Forecasting Hotel Arrival and Occupancy Using Monte Carlo Simulation. Retreived February 20, 2015, from https://alumnus.alumni.caltech.edu/ amir/hotelsim1.pdf

\section{Note}

Note 1. Adapted from Frechtling, D. C. (2001). Forecasting Tourism Demand: Methods and Strategies, Butterworth Heinemann, Oxford, pp. 95-97. 